\title{
Constraint Based Design of Multipole Field Electromagnetic Launcher using Gauss Method
}

\author{
Srichandan Kondamudi, Mallikarjuna Rao Pasumarthi
}

\begin{abstract}
Initiatives in electromagnetic propulsion all over the world are aimed at the development of electromagnetic launchers. This paper presents the constraint based design of Multipole Field Electromagnetic Launcher (MFEL). A design algorithm is developed based on Gauss iterative method. Muzzle velocity is considered as the objective function and the length, diameter and thickness of the accelerating coil are considered as constraints. The results for hexapole, octapole, decapole, dodecapole and hexadecapole cases are compared and tabulated.

Index Terms: Electromagnetics; Flux Distribution; Lorentz force; electromagnetic launcher.
\end{abstract}

\section{INTRODUCTION}

In present century, the constantly increasing levels of electrical power on the new developed systems and having potential of developing huge launch velocity allow Electromagnetic Propulsion to be very realistic and prominent alternative to chemical propulsion. Multipole Field Electromagnetic Launchers (MFEL) is one of the radial electromagnetic launcher which can produce larger radial magnetic field compared with the axial magnetic field [1]. Zhu et al. [1]-[4], proposed the basic design and analysis of MFEL; Xinpeng et al. [6] introduced the combination of rails but no specific inductance values were mentioned; Luo et al. [7] analyzed different connection patterns of MFEL and experimentally tested a single-stage launcher, but the analysis was carried out excluding the leakage fluxes. Design algorithm using Gauss method considering different constraints for various cases was not developed in any of the available literature.

In this paper, a user-interactive algorithm is developed to design a Multipole Field Electromagnetic launcher (MFEL) based on the parametric constraints with the help of Gauss method. Comparison of design parameters for different cases such as hexapole, octapole, decapole, dodecapole and hexadecapole, are tabulated. Moreover, the inductance value obtained was validated in FEM analysis [18].

\section{DESIGN ASCEPTS OF SINGLE STAGE MFEL}

\section{A. Launcher Model}

The Multipole Field EML is a radial electromagnetic launcher, which has multiple coils around the projectile and a spiral catapult coil [1]-[4]. The spiral catapult coil will provide the initial acceleration of the projectile, because the initial pull-in acceleration is less in radial electromagnetic launchers. And the multiple coils will guide the projectile.

Revised Manuscript Received on August 20, 2019.

Srichandan Kondamudi *, Electrical Engineering, Andhra University, Visakhapatnam, India.

MallikarjunaRao Pasumarthi, Electrical Engineering, Andhra University, Visakhapatnam, India.
The acceleration coils and catapult coil are energized from a capacitor bank. Fig. 1 shows the arrangement of a Single stage Multipole Field EML.

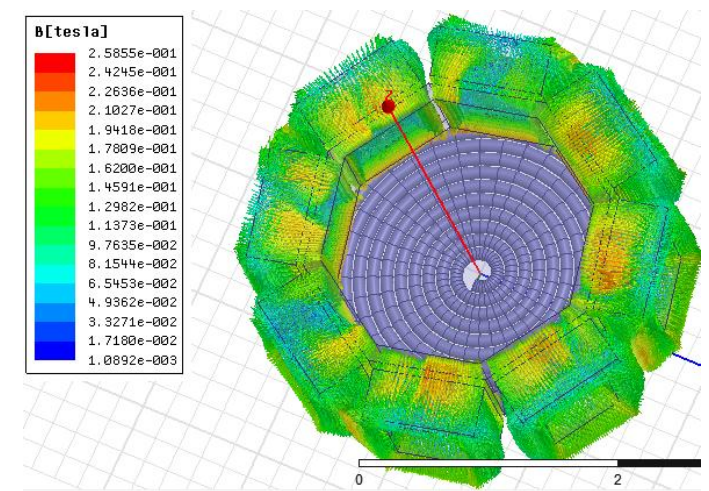

Fig.1. Arrangement of Single stage Multipole Field EML

\section{B. Design Parameters}

The design parameters of accelerating coil for a single stage Multipole Field EML are presented in Table I.

Table I. Design Parameters of Accelerating Coils

\begin{tabular}{ll}
\hline Symbol & Description \\
\hline $\mathbf{t}_{\mathbf{m a x}}$ & Maximum thickness of the coil \\
$\mathbf{d}_{\mathbf{w}}$ & Diameter of the wire \\
$\mathbf{t}$ & Thickness of the coil \\
$\mathbf{l}_{\mathbf{c}}$ & Length of the Coil \\
$\mathbf{l}_{\mathbf{g}}$ & Air-gap length \\
$\mathbf{d}_{\mathbf{p}}$ & Diameter of the projectile \\
$\mathbf{h}_{\mathbf{m}}$ & Thickness of the Projectile \\
$\mathbf{w}_{\mathbf{c}}$ & Breath of the Coil \\
$\mathbf{w}_{\mathbf{p}}$ & Side length of the projectile \\
$\mathbf{N}$ & Number of turns \\
$\mathbf{h}_{\mathbf{c}}$ & Height of the coil \\
\hline
\end{tabular}

Turns per layer

Turnsperlayer $=f\left(\right.$ tmax,$\left.d_{w}\right)$

Winding thickness

$t=f$ (number of turns, $d_{w}$, fill factor $)$

Length of the Coil

$l_{c}=f\left(\right.$ number of layers, $\left.d_{w}\right)$

Length of the Wire

$l_{w}=f\left(w_{c}, h_{c}\right)$

Equivalent Resistance

$\mathrm{R}_{\text {total }}=f\left(1_{\mathrm{w}}, \mathrm{w}_{\mathrm{c}}, \mathrm{h}_{\mathrm{c}}\right.$, number of layers $)$

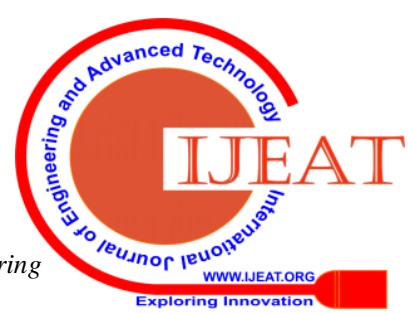




\section{Constraint based Design of Multipole Field Electromagnetic Launcher using Gauss Method}

Equivalent Inductance

$\mathrm{L}_{\mathrm{eq}}=f\left(\mu_{\mathrm{o}}, \mu_{\mathrm{r}}, \mathrm{w}_{\mathrm{c}}, \mathrm{h}_{\mathrm{c}}, \mathrm{t}, \mathrm{l}_{\mathrm{g}}, \mathrm{l}_{\mathrm{p}}, \mathrm{w}_{\mathrm{p}}, \mathrm{N}\right)$

Where $\mu_{0}$ is permeability of the air, $\mu_{\mathrm{r}}$ is relative permeability of the projectile.

The equation 6 for the inductance is obtained using the flux distribution method [11]-[14]. With reference to the flux flow diagram as shown in Fig. 2, various flux paths are identified. The flux path is assumed to have a flux of $\phi$ in the induction coil. It crosses the air gap, splits evenly in the projectile, and then re-crosses the air gap to the other side of the coil.

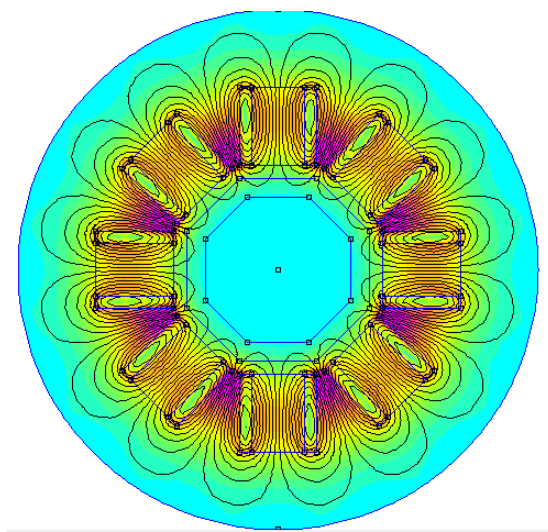

Fig. 2.Flux lines flow in MFEL when projectile inside

The Lorentz force generated on the projectile by the acceleration coil is derived from the principle of electro-mechanical energy conversion. The expression is

$$
\mathrm{F}=0.5 * \mathrm{i}^{2} * \mathrm{dL} / \mathrm{dx}
$$

\section{DESIGN ASCEPTS OF SPRIAL CATAPULT COIL}

The induction coils cannot provide the initial thrust because of radial flux distribution [3]. Due to which the projectile cannot move smoothly in the axis of the barrel. To overcome this problem, catapult coil is used in the Multipole Field EML, which provides the initial thrust such that the projectile is given the direction in which way it has to propel. Fig. 3 shows the arrangement of spiral catapult coil. The design parameters of spiral catapult coil for a single stage Multipole Field EML are presented in Table II.

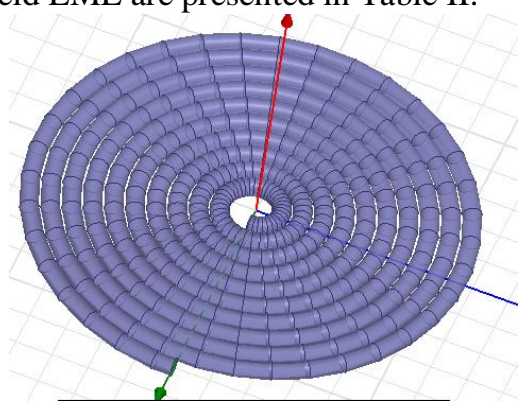

Fig. 3. Arrangement of Spiral Catapult coil

Table II. Design Parameters of Accelerating Coils

\begin{tabular}{ll}
\hline Symbol & Description \\
\hline $\mathbf{d}_{\text {outersp }}$ & Outer Diameter of the Spiral coil \\
$\mathbf{d}_{\text {innersp }}$ & Inner Diameter of the Spiral coil \\
$\mathbf{d}_{\mathbf{w s p}}$ & Diameter of the wire \\
$\mathbf{d}_{\mathbf{w} 2 \mathbf{w}}$ & Distance between winding to winding \\
$\mathbf{N}_{\mathbf{s p}}$ & Number of turns in spiral coil \\
\hline
\end{tabular}

The inductance of the catapult coil

$\mathrm{L}_{\mathrm{sp}}=f\left(\mathrm{~d}_{\text {outersp }}, \mathrm{d}_{\text {innersp }}, \mathrm{d}_{\mathrm{wsp}}, \mathrm{d}_{\mathrm{w} 2 \mathrm{w}}, \mathrm{N}_{\mathrm{sp}}\right)$

The force between the projectile and the catapult coil is based on the skin-depth the projectile is given as

$\mathrm{F}_{\text {spiral }}=f\left(\mathrm{~d}_{\text {outersp }}, \mathrm{d}_{\text {innersp }}, \mathrm{d}_{\mathrm{wsp}}, \mathrm{d}_{\mathrm{w} 2 \mathrm{w}}, \mathrm{z}, \theta, \mathrm{I}\right)$

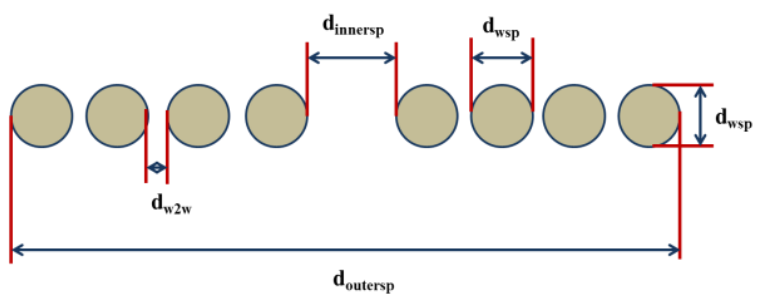

Fig. 4.Design parameters of Spiral Catapult Coil (Side View)

\section{DESIGN ALGORITHM}

The main objective in the design of Multipole Field EML is to obtain the maximum velocity (required velocity) considering the physical dimensions such as length of the coil, number of turns, number of layers, thickness, and height of the coil as the constraints. The objective function used in the design procedure of the Multipole Field EML is

$$
\mathrm{v}_{\max }=f\left(\mathrm{w}_{\mathrm{c}}, \mathrm{h}_{\mathrm{c}}, \mathrm{t}, \mathrm{l}_{\mathrm{g}}, \mathrm{l}_{\mathrm{p}}, \mathrm{w}_{\mathrm{p}}, \mathrm{N}, \text { nop, nol, } \mathrm{m}_{\mathrm{g}}\right)
$$

Where nol is number of layers; nop is number of poles; $\mathrm{m}_{\mathrm{g}}$ is mass of the projectile.

The design procedure is elucidated with the help of flowchart shown in Fig. 5. The user-defined parameters like required velocity, weight of projectile, projectile length, input voltage and side length of the projectile are initiated. Then based on the number of poles, the diameter of the projectile is calculated. Thickness of the coil and length of the coil are the parameter which have boundary conditions, so the thickness of the coil and the length of the coil are considered as constraints.

$$
\begin{aligned}
& 0<\mathrm{t}<\mathrm{t}_{\max }(11) \\
& 0<\mathrm{l}_{\mathrm{c}}<\mathrm{d}_{\mathrm{b}}(12)
\end{aligned}
$$

By satisfying the constraints, if the error between the required velocity and calculated velocity is in a permissible limit then the problem is converged. If the error is not in tolerance limit then number of turns and number of layers are incremented. 


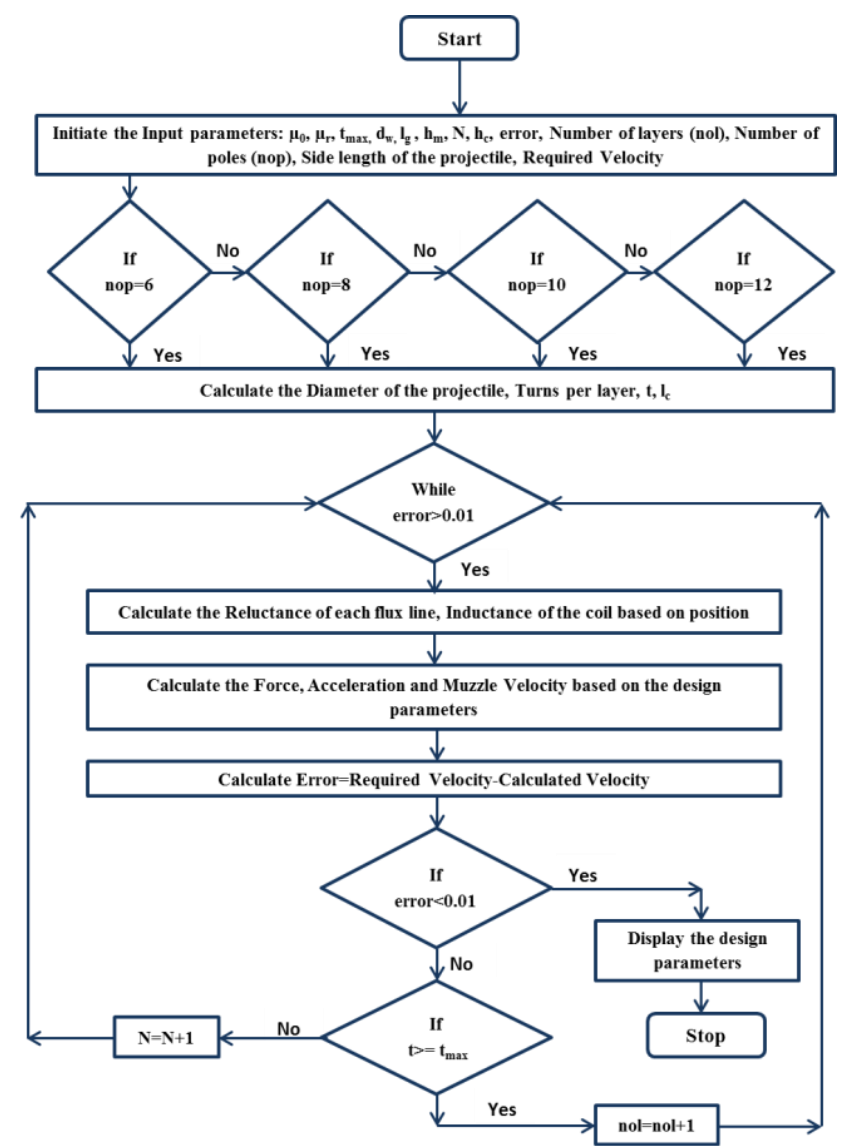

Fig. 5.Design Flowchart

\section{RESULT AND ANALYSIS}

The input specifications considered for the design are presented in Table III.

Table III. Input Parameters

\begin{tabular}{ll}
\hline Permeabilityof the Air & $4 * \mathrm{pi}^{*} 10^{\wedge}-7 \mathrm{H} / \mathrm{m}$ \\
Permeability of the Pure Iron & 5000 \\
Diameter of the Wire & $0.45 \mathrm{~mm}$ \\
Length of air-gap & $1 \mathrm{~mm}$ \\
Side length of the projectile & $20 \mathrm{~mm}$ \\
Length of the projectile & $25 \mathrm{~mm}$ \\
Voltage & $500 \mathrm{~V}$ \\
Thickness of the projectile & $10 \mathrm{~mm}$ \\
Weight of the projectile & $1 \mathrm{~kg}$ \\
Required velocity & $10 \mathrm{~m} / \mathrm{sec}$ \\
\hline
\end{tabular}

\section{A. Inductance Profile}

The inductance profile of a single stage Hexapole Field EML is shown in Fig.6.

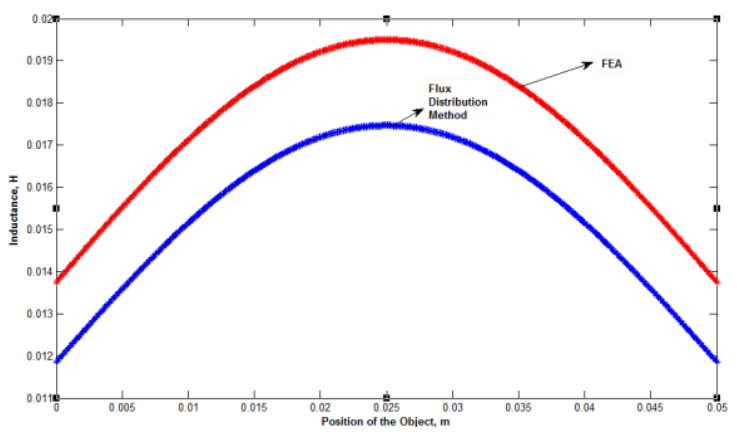

Fig. 6.Inductance Profile compared with FEA
The maximum and minimum inductances of the accelerating coils are $17.5 \mathrm{mH}$ and $12 \mathrm{mH}$ respectively. Inductance profile is validated using Finite Element Analysis (FEA) and the comparison is plotted in Fig. 6.

Table IV. Inductance Profile for various number of poles

\begin{tabular}{|l|l|l|l|l|l|}
\hline & $\begin{array}{l}\text { Hexa } \\
\text { pole }\end{array}$ & $\begin{array}{l}\text { Octa } \\
\text { pole }\end{array}$ & $\begin{array}{l}\text { Deca } \\
\text { pole }\end{array}$ & $\begin{array}{l}\text { Dodeca } \\
\text { pole }\end{array}$ & $\begin{array}{l}\text { Hexa } \\
\text { deca } \\
\text { pole }\end{array}$ \\
\hline $\mathrm{L}_{\min }(\mathrm{H})$ & 0.0081 & 0.0062 & 0.0058 & 0.0045 & 0.0037 \\
\hline $\mathrm{L}_{\max }(\mathrm{H})$ & 0.0175 & 0.0175 & 0.0183 & 0.0179 & 0.0179 \\
\hline
\end{tabular}

From Table IV, it is observed that minimum inductance is decreasing, as the number of poles has increased. And the maximum inductance is similar for some of the cases because, when pole increases the requirement of turns will reduce, to achieve the same required velocity.

\section{B. Design Results}

Based on the design algorithm, a user-interactive program is developed and values for various cases were tabulated.

Table V. Design values of Hexapole EML

\begin{tabular}{|l|l|}
\hline Diameter of Projectile & $40 \mathrm{~mm}$ \\
\hline Velocity required & $10 \mathrm{~m} / \mathrm{sec}$ \\
\hline Velocity Obtained & $10.086639 \mathrm{~m} / \mathrm{sec}$ \\
\hline Force Obtained & $101.740294 \mathrm{~N}$ \\
\hline Number of turns for each layer & 22 \\
\hline Number of turns & 352 \\
\hline Number of layers & 16 \\
\hline Height of the Coil & $5.906 \mathrm{~mm}$ \\
\hline Thickness of the Coil & $10 \mathrm{~mm}$ \\
\hline No. of iterations & 329 \\
\hline
\end{tabular}

Table VI. Design values of Octapole EML

\begin{tabular}{|l|l|}
\hline Diameter of Projectile & $52.263 \mathrm{~mm}$ \\
\hline Velocity required & $10 \mathrm{~m} / \mathrm{sec}$ \\
\hline Velocity Obtained & $9.997397 \mathrm{~m} / \mathrm{sec}$ \\
\hline Force Obtained & $99.947951 \mathrm{~N}$ \\
\hline Number of turns for each layer & 22 \\
\hline Number of turns & 286 \\
\hline Number of layers & 13 \\
\hline Height of the Coil & $4.737 \mathrm{~mm}$ \\
\hline Thickness of the Coil & $10.125 \mathrm{~mm}$ \\
\hline No. of iterations & 263 \\
\hline
\end{tabular}

Table VII. Design values of Decapole EML

\begin{tabular}{|l|l|}
\hline Diameter of Projectile & $64.72 \mathrm{~mm}$ \\
\hline Velocity required & $10 \mathrm{~m} / \mathrm{sec}$ \\
\hline Velocity Obtained & $10.195569 \mathrm{~m} / \mathrm{sec}$ \\
\hline Force Obtained & $103.949621 \mathrm{~N}$ \\
\hline Number of turns for each layer & 22 \\
\hline Number of turns & 242 \\
\hline Number of layers & 11 \\
\hline Height of the Coil & $4.347 \mathrm{~mm}$ \\
\hline Thickness of the Coil & $9.675 \mathrm{~mm}$ \\
\hline No. of iterations & 240 \\
\hline
\end{tabular}

Table VIII. Design values of Dodecapole EML

\begin{tabular}{|l|l|}
\hline Diameter of Projectile & $77.27 \mathrm{~mm}$ \\
\hline Velocity required & $10 \mathrm{~m} / \mathrm{sec}$ \\
\hline Velocity Obtained & $10.060007 \mathrm{~m} / \mathrm{sec}$ \\
\hline Force Obtained & $101.203738 \mathrm{~N}$ \\
\hline Number of turns for each layer & 22 \\
\hline Number of turns & 220 \\
\hline Number of layers & 10 \\
\hline
\end{tabular}




\begin{tabular}{|l|l|}
\hline Height of the Coil & $3.568 \mathrm{~mm}$ \\
\hline Thickness of the Coil & $10.125 \mathrm{~mm}$ \\
\hline No. of iterations & 197 \\
\hline
\end{tabular}

Table VIII. Design values of Hexadecapole EML

\begin{tabular}{|l|l|}
\hline Diameter of Projectile & $102.51 \mathrm{~mm}$ \\
\hline Velocity required & $10 \mathrm{~m} / \mathrm{sec}$ \\
\hline Velocity Obtained & $10.018893 \mathrm{~m} / \mathrm{sec}$ \\
\hline Force Obtained & $100.378224 \mathrm{~N}$ \\
\hline Number of turns for each layer & 22 \\
\hline Number of turns & 176 \\
\hline Number of layers & 8 \\
\hline Height of the Coil & $3.178 \mathrm{~mm}$ \\
\hline Thickness of the Coil & $8.225 \mathrm{~mm}$ \\
\hline No. of iterations & 173 \\
\hline
\end{tabular}

Table V-IX shows that the design values of various cases of Multipole Field EML. It is observed that when number of poles increases, the number of turns, number of layers, height, thickness and number of iterations has reduced. And in all the cases the required velocity, applied voltage and mass of the projectile are maintained same.

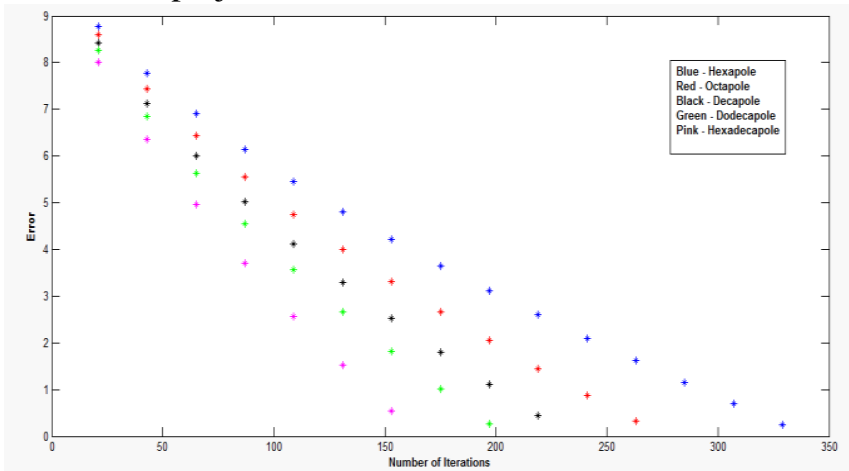

Fig. 7.Inductance Profile compared with FEA

Fig.7. explains the relation between the number of iterations and velocity error. It is observed that when number of poles increases, the force generated will increase which will lead to achieve the required velocity in less number of iterations. And the force profile of various cases is plotted in Fig. 8. It is observed that the values of force are same, as the required velocity is same in all the cases.

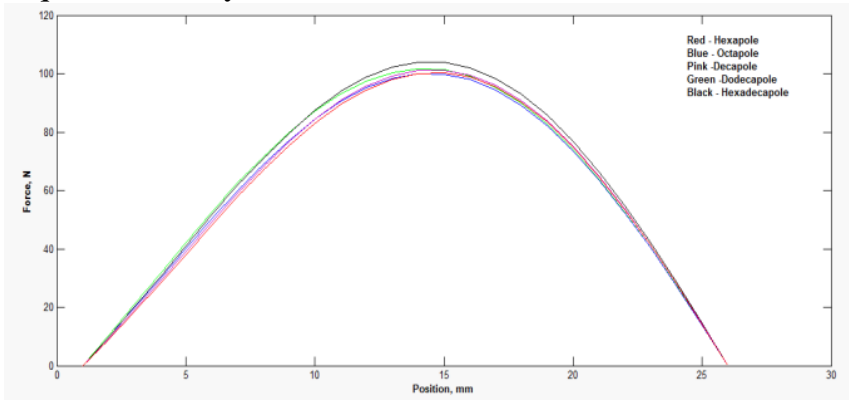

Fig. 8.Force profile based on position of the projectile

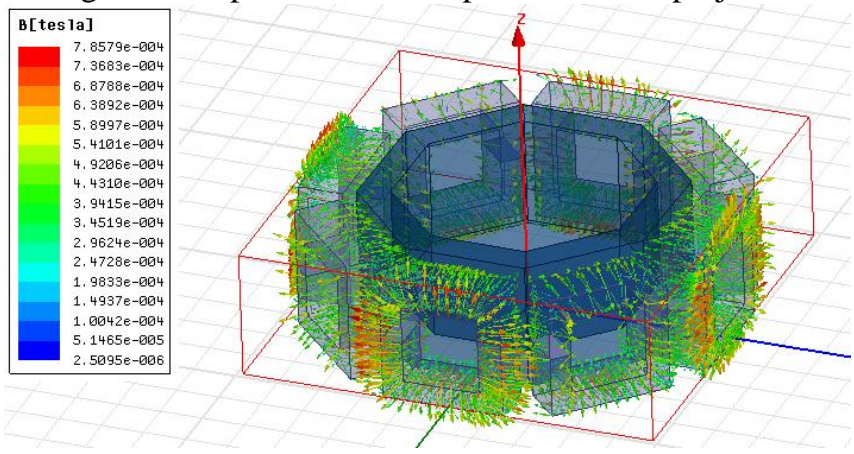

Fig. 9.Flux Density profile of MFEL
In Fig. 8, the force profiles for different cases are plotted. It is observed that maximum force values are same because the required velocity in each case is same. Fig. 9 shows flux distributions in the Multipole Field EML.

\section{CONCLUSION}

This paper has presented a constraint based design algorithm and numerical analysis for Multipole Field Electromagnetic Launcher (MFEL). The design algorithm is developed based on the Gauss iterative method. The objective is to achieve the required muzzle velocity. The accelerating coil length, diameter and thickness are considered as constraints. A comparative analysis for hexapole, octapole, decapole, dodecapole and hexadecapole cases is done.

From the analysis, it is observed that when number of poles are increasing, the required number of turns and number of layers are decreasing when the muzzle velocity is maintained constant for all cases. From this, it can be claimed that the required copper in the system will decrease, which says that the cost of the electromagnetic launcher will decrease. Hence it is to be concluded that the proposed design has considerable effect in improving the launch performance, structure and configuration of Multipole Field EL. Moreover, User-interactive algorithm has provided flexibility in choosing different required velocities by considering different constraints.

\section{REFERENCES}

1. Yan, Z., Long, X., Lu, F., Wang, Y., Liu, H., "Study of Single-Stage Double-Armature Multipole Field Electromagnetic Launcher", in IEEE Transactions On Plasma Science, vol. 45, no. 8, 2017, pp. 2381-2386.

2. Y. Zhu, Y. Wang, Z. Yan, L. Dong, X. Xie, and H. Li, "Multipole field electromagnetic launcher," in IEEE Transactions Magnetics., vol. 46, no. 1, 2010,pp 2622- 2627.

3. XinpengXue, Tao Shu, Zhiyong Yang, and Gang Feng, "Toroidal Field Electromagnetic Launcher”, in IEEE Transactions on Plasma Science, vol. 44, no. 10, 2016, pp2393-2398.

4. Zhu Yingwei, Wang Yu, Chen Weirong, Yan Zhongming, and Li Haitao, "Analysis and Evaluation of Three-Stage Twisty Octapole Field Electromagnetic Launcher”, in IEEE Transactions On Plasma Science, vol. 40, no. 5, 2012, pp. 1399-1406.

5. Frederick W. Grover, "Inductance Calculation", Dover Publication, 2009.

6. XinpengXue, Tao Shu, Zhiyong Yang, and Gang Feng, "A New Electromagnetic Launcher by Sextupole Rails: Electromagnetic Propulsion and Shielding Numerical Validation", IEEE Transactions On Plasma Science, vol. 45, No. 9, September 2017.

7. Luo, W., Wang, Y., Gui, Z., Yan, Z., Chen, W., "Connection pattern research and experimental realization of single stage multipole field electromagnetic launcher", in IEEE Transactions on Plasma Science, vol. 41, no. 11, 2013, pp. 3173-3179.

8. Musolino, A., Rizzo, R., Tripodi, E., "Travelling wave multipole field electromagnetic launcher: An SOVP analytical model", in IEEE Transactions on Plasma Science, vol. 41, no.5, 2013, pp. 1201-1208.

9. AhmadaliKhatibzadeh, M.R. Besmi, "Improve Dimension of Projectile For Increasing Efficiency of Electromagnetic Launcher," in $4^{\text {th }}$ Power Electronics, Drive Systems \& Technologies Conference (PEDSTC2013), 2013, Tehran, Iran. 78-1-4673-4484-5/13.

10. Smythe, w., (1939), "Static and Dynamic Electricity," McGraw-Hill Book Co., Inc., New York, First edition (1939), 316.

11. SrichandanKondamudi, MallikarjunaRaoPasumarthi, "Computations of Magnetic Forces in Multipole Field Electromagnetic Launchers", in International Journal of Mathematical, Engineering and Management Sciences, vol. 4, No. 3, 2019, pp.761-774. 
12. SrichandanKondamudi, MallikarjunaRaoPasumarthi, "Design and Analysis of Cored type Multipole Field Electromagnetic Launcher (C-MFEML)", in International Journal of Innovative Technology and Exploring Engineering(IJITEE), vol. 8, no.6, 2019, pp. 391-395.

13. K.SriChandan, P. MallikarjunaRao, "A Mathematical Formulation of Inductance for Multipole Field Electromagnetic Launcher," in International Journal of Pure and Applied Mathematics, vol. 118, no. 24, 2018, pp. 1-13.

14. K.Sri Chandan, P. Mallikarjuna Rao, "Comprehensive Analysis of Octapole Electromagnetic Launcher", in International Journal for Research in Applied Science \& Engineering Technology, vol 5, no.10, 2017, pp. 2146-2154.

\section{Authors ProfiLe}

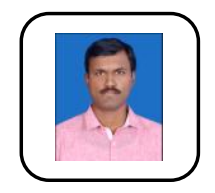

SrichandanKondamudi, had completed his Bachelor's Degree in Electrical and Electronics Engineering in 2005, Master's Degree in Power Systems and Automation Engineering in 2008. Presently, He is research scholar in department of electrical engineering, Andhra University. His research interests are Electrical machine design, Design and control of Special electrical drives and Design of electromagnetic launching systems..

MallikarjunaRao Pasumarthi is currently with Andhra University, Visakhapatnam, Andhra Pradesh, India, where he is a Professor of Electrical Engineering. His research interests include control systems, Design and analysis of specific purpose electrical machines and their control. 